\title{
Sociobiology
}

RESEARCH ARTICLE - ANTS

\section{Flight and digging effort in leaf-cutting ant males and gynes}

\author{
EJ SILVA, RS CAMARGO, LC FORTI
}

Universidade Estadual Paulista - UNESP, Botucatu, SP, Brazil

\section{Article History \\ Edited by \\ Kleber Del-Claro, UFU, Brazil \\ Received 26 May 2014 \\ Initial acceptance 17 July 2014 \\ Final acceptance 10 September 2014}

\section{Keywords}

Ants, carbohydrates, lipids, social insects

\section{Corresponding author}

Roberto da Silva Camargo

Laboratório de Insetos Sociais-Praga

Departamento de Produção Vegetal

Faculdade de Ciências Agronômicas

UNESP, 18603-970, Caixa Postal 237,

Botucatu, SP, Brazil

E-Mail: camargobt@hotmail.com

\begin{abstract}
The nuptial flight and nest digging are high intensity activities which consume body reserves. The flight and digging effort was quantified by measuring the carbohydrate and total lipids content in males and females before and after the nuptial flight, and the queen's digging effort during the foundation. The digging effort was quantified by experimentally stimulating the queens to dig a nest - one, two or three consecutive times - compared to the queens that did not dig. The colorimetric method was used to determine the soluble carbohydrates and extraction method of immersion was used to determine the total lipids. The results showed significant loss of carbohydrates and total lipids in males and females after the flight. On average the males contained $0.027 \mathrm{mg}$ of soluble carbohydrates before the nuptial flight, and $0.005 \mathrm{mg}$ after the nuptial flight, and the females contained $0.129 \mathrm{mg}$ of soluble carbohydrates before the nuptial flight, and $0.079 \mathrm{mg}$ after the nuptial flight. For the males the percentage of lipids decreased from $5.27 \pm 1.07 \%$ to $2.60 \pm 0.63 \%$ and for females from $36.46 \pm 4.86 \%$ to $32.62 \%$ after the nuptial flight. The digging effort of the queen caused a slight reduction in total carbohydrates, it was without digging 0.054 $\mathrm{mg}$, normal digging $0.055 \mathrm{mg}$, double digging $0.045 \mathrm{mg}$ (decrease of 20,22\%), and triple digging $0.044 \mathrm{mg}$ (decrease of $20 \%$ ) per queen. Based on our results we conclude that the carbohydrate content is the main energetic resource used for the nuptial flight and nest digging, for males and gynes of leaf-cutting ants.
\end{abstract}

\section{Introduction}

Annually, mature Atta colonies produce male and female winged ants that leave the colony to form new colonies and thereby, continue and perpetuate the species (Hölldobler \& Wilson, 1990). The nuptial flight of leaf-cutting ants may occurs in the morning or afternoon according to species, controlled by the first rains starting the rainy season (Staab \& Kleineidam, 2014 for Atta vollenweideri), with the males forming "swarms" of $200 \mathrm{~m}$ in diameter and heights over $150 \mathrm{~m}$ above ground level for Atta capiguara (Amante, 1972). The flying distance varies according to species and the air flow speed. It is known that females of Atta texana can fly at a speed of $5.33 \mathrm{~ms}^{-1}$, indicating a distance of $10.4 \mathrm{~km}$ (Moser, 1967); Atta sexdens at a speed of $1.57 \mathrm{~ms}^{-1}$, with a possible distance of $11.1 \mathrm{~km}$ (Jutsum \& Quinlan, 1978), and field observations have shown a dispersion of queens of $9.6 \mathrm{~km}$ for the this species (Cherrett, 1968). After the nuptial flight and copulation, a queen of Atta sexdens digs a vertical tunnel of about
$15 \mathrm{~cm}$ and a chamber within which she is enclosed, caring for fungus culture and brood (Autuori, 1942).

The nest digging takes on average about 6 to 10 hours (Autuori, 1942), with about 300 trips to stack the excavated soil by the queen, each trip lasting from 30 seconds to 30 minutes (Ribeiro, 1972). Because this activity is very intense, it is assumed that the energetic cost of the excavation is high. There is a few data available in the literature regarding the amount of energy required by the queen for digging the nests (Camargo \& Forti, 2013 A). The energy required is removed from carbohydrate reserves, because the lipid content is spared when queen dug the nest (Camargo \& Forti, 2013 B).

The digging effort significantly affects the survival of queens of Atta sexdens rubropilosa. At the first week after an extra digging effort, (successively digging of two or three nests) there is a higher mortality in queens. It can probably be stated that the mortality of the queens was caused by the depletion of body reserves (Camargo et al., 2011). Besides, in the claustral 

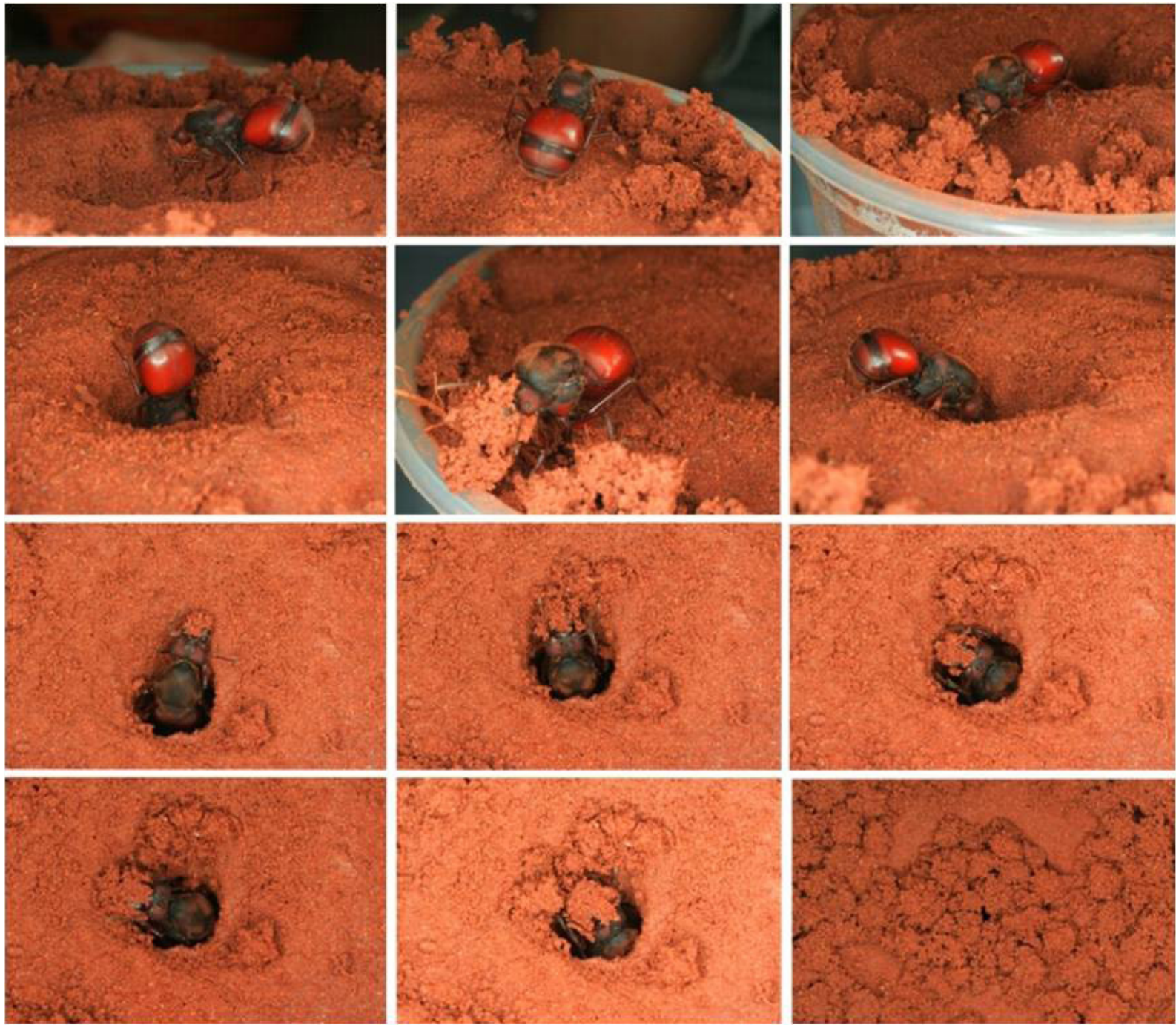

Fig 1. Behavioral sequence of nest digging by the queen, illustrating the "turning point", in other words, queen digs with head down, and when it can turn around into the chamber, it carries the soil pellet with head up until enclosure.

phase, queens loose about $40 \%$ of their body weight after 60 days (Della Lucia et al., 1995), reaching minimum body mass before the first workers begin to forage. When foraging starts, the queen recovers her body mass, due to nourishment in the colony (Della Lucia et al., 1990, Camargo et al., 2013).

The goal of the present study was to measure the soluble carbohydrate and lipid contents of gynes and males consumed before and after the nuptial flight, and soluble carbohydrate consumed before and after the nest excavation by the queen.

\section{Material and Methods}

Collecting Atta sexdens rubropilosa females and males before and after the nuptial flight.

We collected females and males (pre-nuptial flight) from three nests of $A$. sexdens rubropilosa over a mound of loose-soil before the nuptial flight. These insects $(\mathrm{N}=40)$ were taken to the laboratory, immediately killed by freezing and analyzed for lipid content.
The mated females (post-nuptial flight) were collected after shedding their wings and beginning to dig start their new colonies $(\mathrm{N}=20)$, and males after their death $(\mathrm{N}=20)$. After the collection, the queens were immediately stored in plastic containers (11 cm in diameter, $8 \mathrm{~cm}$ high), containing $1 \mathrm{~cm}$ of plaster at the bottom to keep the air moist. The queens and males were transported to the Laboratório de Insetos Sociais-Praga FCA/UNESP - Botucatu, SP, Brazil, this travel took 30 minutes.

\section{Digging Effort}

This experimental set up was previously performed according to Camargo et al. (2011) and Camargo and Forti (2013 B). One hour after the nuptial flight, the queens were placed in tubes filled with soil $(25 \mathrm{~cm}$ high and $10 \mathrm{~cm}$ in diameter), removed at $60 \mathrm{~cm}$ in depth, at a density of $1.6 \mathrm{~g} / \mathrm{cm}^{3}$. The queens did not start laying eggs before the experiments. Four experimental series were performed, as follow:

1) Without digging: Queens did not dig at all, and were directly placed singly in a plastic container; 
2) Single digging: Queens were allowed to dig in the tube filled with soil, until they sealed the excavated tunnel;

3) Double digging: Queens were allowed to dig twice in the tube filled with soil, by being immediately removed from the dug chamber and again met in a new digging tube, in which they started to excavate a second nest;

4) Triple digging: Queens were allowed to dig thrice in the tube filled with soil, by being met immediately in two new digging tubes after the first excavation.

For all four groups, the queens were removed from the tubes and frozen in order to determine the soluble carbohydrates.

In addition to the soluble carbohydrate content, the length of the excavated tunnel was determined, as well as the excavated chamber dimensions (length, width and height). The volume of excavated soil was also measured by direct weighing in a semi-analytical balance. The queens' digging time was measured to assess their performance and effort. The queens' digging time was observed in 3 ways: First - time spent in tunnel excavation, Second - time spent in chamber excavation, and Third - time spent in tunnel and chamber excavation, when the observer lost queen's turning point (Fig 1). This behavioral sequence was studied by Fröhle and Roces (2012).

\section{Determination of carbohydrates}

The colorimetric determination of the soluble carbohydrates was achieved by the method of Dubois et al. (1956), based on the reaction of carbohydrates, sulfuric acid and phenol. The reaction generates a yellow-orange color which is sensitive and stable. The absorbance was determined on a Beckman DU640 spectrophotometer. The blank received water in place of the extracts. Glucose was used as standard $(\mathrm{C}=90.531 \mathrm{Abs}+3.7125$, $\left.\mathrm{R}^{2}=0.992\right)$. The values were expressed as $\mathrm{mg}$ of total sugars.

\section{Determining total lipid content}

Males and females before and after the nuptial flight were killed by freezing and then subjected to the experimental procedure used by Seal (2009). The procedure was as follow: 1) Fresh mass of males and females was individually determined; 2) Queens were dried for 24 hours at $70^{\circ} \mathrm{C}$ and their dry mass was determined; and 3) The lipid content was extracted with petroleum ether (bp $40-60^{\circ} \mathrm{C}$ ) for 24 hours and the queens weighed again. This procedure was repeated for 72 hours of extraction. The percentage of total fat content was calculated using the formula: 100x (DM - FFDM)/DM, where DM is the dry mass and FFDM is dry and fat free mass. The energy content of the ants was obtained by multiplying their lean mass by 18.87 $\mathrm{J} \mathrm{mg}^{-1}$ and their fat mass by $39.33 \mathrm{~J} \mathrm{mg}^{-1}$ (Peakin, 1972).

\section{Statistical analysis}

The total lipid and soluble carbohydrate content of males and queens before and after the nuptial flight and nest digging effort were compared using a paired t-test ( $\alpha$ $=0.05$ ). The data of the excavation effort were subjected to the ANOVA of repeated measures $(\alpha=0.05)$, comparing the variable total digging time, overall tunnel length and excavated soil of each experimental series. The analysis was performed using the SigmaPlot 11.0 program.

\section{Results}

\section{Nuptial flight effort}

The average fresh masses of male and females of $A$. sexdens rubropilosa before nuptial flight were $103.6 \pm 18.6 \mathrm{mg}$ and $656.7 \pm 75.1 \mathrm{mg}$, whereas the masses of male and females after nuptial flight which had mated and flew were 154.3 \pm 7.9 $\mathrm{mg}$ and $631.2 \pm 38.8 \mathrm{mg}$, respectively (Table 1).

For males and females we verified a significant loss of soluble carbohydrate after the flight. On average the males contained $0.027 \mathrm{mg}$ of soluble carbohydrates before the nuptial flight, and $0.005 \mathrm{mg}$ after the nuptial flight (reduction of $81.48 \%$ ) ( $\mathrm{t}$ test $=7.661$, d.f. $=18, \mathrm{P}<0.0001$ ). On average the females contained $0.129 \mathrm{mg}$ of soluble carbohydrates before the nuptial flight, and $0.079 \mathrm{mg}$ after the nuptial flight (reduction of $38.76 \%$ ), differing significantly between them ( $\mathrm{t}$ test, $\mathrm{t}=4.718$, d.f. $=18, \mathrm{P}<0.0001$ ).

Lipids represented $36.46 \pm 4.86 \%$ and $5.27 \pm 1.07 \%$ of the body mass of females and males before nuptial flight, respectively. This percentage decreased to $35.00 \pm 2.28 \%$ in females and $2.60 \pm 0.63 \%$ in males who mated and flew (Table 1). As expected, significant differences were detected in the percentage of lipids of males before and after the nuptial flight (ANOVA, $\mathrm{F}_{1 ; 19}=89.051, \mathrm{P}<0.001$ ). But, the percentage of lipids of females who had and had not flown were not significantly different (ANOVA, $\mathrm{F}_{1: 19}=1.400, \mathrm{P}=0.242$ ). The energy content was $8563.24 \pm 1668.76 \mathrm{~J}$ for females before nuptial flight, $8413.37 \pm 802.56 \mathrm{~J}$ for females who had flown (Table 1).

Table 1. Mean and standard deviation $(\mathrm{m} \pm \mathrm{sd})$ of masses $(\mathrm{mg})$, percentage of fat and energy content $(\mathrm{J})$ in the bodies of males and female of Atta sexdens rubropilosa before and after nuptial flight.

\begin{tabular}{lllll}
\hline & Male before NF $(\mathrm{n}=20)$ & Male after NF $(\mathrm{n}=20)$ & Female before NF $(\mathrm{n}=20)$ & Female after NF $(\mathrm{n}=20)$ \\
\hline Fresh Mass $(\mathrm{mg})$ & $103.68 \pm 18.61$ & $154.29 \pm 7.96$ & $656.72 \pm 75.05$ & $631.18 \pm 38.81$ \\
Dry mass (mg) & $35.17 \pm 5,60$ & $53.02 \pm 2.74$ & $323.69 \pm 53.64$ & $322.85 \pm 25.20$ \\
Lean mass (mg) & $33.31 \pm 5.32$ & $51.63 \pm 2.54$ & $203.68 \pm 25.75$ & $209.39 \pm 11.63$ \\
Lipid content (mg) & $1.86 \pm 0.51$ & $1.39 \pm 0.41$ & $120,01 \pm 31.39$ & $113.46 \pm 15.77$ \\
Lipid percentage (\%) & $5.27 \pm 1.07$ & $2.60 \pm 0.63$ & $36.46 \pm 4.86$ & $35.00 \pm 2.28$ \\
Energy content $(\mathrm{J})$ & - & - & $8563.24 \pm 1668.76$ & $8413.37 \pm 802.56$ \\
\hline
\end{tabular}




\section{Discussion}

In the single digging, the average time spent for the queens was of $383.21 \pm 59.01(\mathrm{~N}=14)$ minutes to dig the tunnel, and $42.21 \pm 40.46(\mathrm{~N}=14)$ minutes for the initial chamber. It was not possible to observe the turning point for some queens, they took an average of $523.75 \pm 164.79(\mathrm{~N}=14)$ minutes to build the entire nest. In the double digging, the average spent time for the queens was of $310.35 \pm 137.94$ $(\mathrm{N}=20)$ minutes to dig the tunnel, and $77.35 \pm 95.19(\mathrm{~N}=20)$ minutes for the initial chamber. Some went into claustral confinement without the observation of the queen's turning point, thus the total digging time was of $305.0 \pm 184.59(\mathrm{~N}=5)$ minutes to build the entire nest. In this experimental series, five queens did not do any digging. In the triple digging, the average spent time for the queens was of $331.21 \pm 169.90$ $(\mathrm{N}=10)$ minutes to dig the tunnel, and $79.30 \pm 89.87(\mathrm{~N}=10)$ minutes for the initial chamber. Some of them enclosure without the observation of the queen's turning point, thus the total digging time was of $347.67 \pm 73.21(\mathrm{~N}=10)$ minutes to build the entire nest. In this experimental series, eight queens did no digging.

The statistical analysis showed that there were differences at double digging (ANOVA, $\mathrm{F}_{1 ; 52}=12,47$, $\mathrm{P}<0.001$ ), where the queen's total digging time was higher at first than in the second digging time. Moreover, there was difference in the triple digging (ANOVA, $\mathrm{F}_{1 ; 77}=5.85, \mathrm{P}<0.05$ ), where the first founding nest in the triple digging experiment takes significantly longer than two following ones (Tukey post test, first versus second, $\mathrm{P}<0.05$; first versus third, $\mathrm{P}<0.01$, second versus third, non significant).

The overall of average removed soil dry mass was $35.66 \pm 6.86 \mathrm{~g}$ for the single, $59.21 \pm 15.38 \mathrm{~g}$ for double and $87.90 \pm 16.98$ for triple digging. There were significant differences among dry mass of soil excavated by the queen, being this amount higher for the triple digging, followed by double digging in the excavated soil (ANOVA, $\mathrm{F}_{2 ; 87}=70,95$, $\mathrm{P}<0.0001$, Tukey post test: first versus second, $\mathrm{P}<0.01$; first versus third, $\mathrm{P}<0.01$; second versus third, $\mathrm{P}<0.01$ ).

The overall tunnel length dug by the queens was $12.00 \pm 2.02 \mathrm{~cm}$ for the single, $19.32 \pm 4.58 \mathrm{~cm}$ for double and $26.62 \pm 6.12 \mathrm{~cm}$ for triple digging. There were differences in the excavated tunnel length (ANOVA: $\mathrm{F}_{2 ; 87}=51.84, \mathrm{P}<0.0001$, Tukey post test: first versus second, $\mathrm{P}<0.01$; first versus third, $\mathrm{P}<0.01$; second versus third, $\mathrm{P}<0.01$ )

Queen's digging effort caused a slight reduction in total carbohydrates when they excavated two and three nests. Queens that did not dig presented $0.054 \mathrm{mg}$ of total carbohydrates, and after a single digging, $0.055 \mathrm{mg}$. On the other hand, after double and triple digging they showed 0.045 $\mathrm{mg}$ and $0.044 \mathrm{mg}$, respectively, which represents a decrease of about 20,22\% of total carbohydrates (ANOVA, $\mathrm{F}_{3 ; 36}=$ $3.1096, \mathrm{P}=0.0376)$.
As expected, total soluble carbohydrate and lipid contents reduced in males and total soluble carbohydrate reduced in gynes of Atta sexdens rubropilosa after the nuptial flight. This result is similar that found by Jutsum and Quinlan (1978) in Atta sexdens. The authors found that $21 \%$ of the dry mass of the winged is carbohydrate, which is completely consumed after the nuptial flight. Similarly, in a study of Formica lugubris, it was demonstrated that carbohydrate (stored as glycogen) is the main energy source for the nuptial flight (Passera et al., 1989). Furthermore, both studies state that lipids are not used as energy for the females' flight, as observed in our study (Table 1) and in Camargo \& Forti (2013 B). In Cataglyphis cursor and Iridomyrmex humilis, the males have higher carbohydrate content when compared with females (Passera \& Keller, 1990). From these studies, it can be assumed that the first energy source to be depleted in the nuptial flight is the carbohydrate reserves. Lipids and proteins degrade at slower rates when compared to carbohydrates, preserving these reserves for the activities after nuptial flight.

It is known that the symbiotic fungus is a rich source of carbohydrates, especially glucose. According to Silva et al. (2003), the glucose concentration in the fungus garden was of $27.7 \mathrm{mg} . \mathrm{g}^{-1}$, about two and a half times higher than

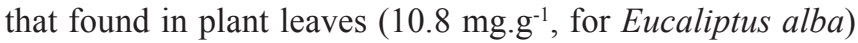
and about six and a half times higher than that found in symbiotic fungi mycelia grown in culture medium $\left(4.3 \mathrm{mg} . \mathrm{g}^{-}\right.$ $\left.{ }^{1}\right)$. Thus, the nourishment from the fungus garden allows the sexual forms to acquire sufficient reserves for the nuptial flight (Fujihara et al., 2012), and the subsequent excavation of the nest by the founding queen, as showed in our study when queens dug two and three time.

With regards to the digging effort, under the experimental conditions, leaf-cutting ant queens excavated the nest (Table 2), as previously described in the literature (Eidmann, 1935; Cunha, 1968; Camargo et al., 2011; Fujihara et al., 2012), first a tunnel, and then a chamber (Fig 1). The depth of the initial chamber, ranging from 8.5 to $15 \mathrm{~cm}$ (Autuori, 1942; Ribeiro, 1972).

Table 2. Mean and standard deviation ( $\mathrm{cm}$ ) of tunnel length and dimensions of the initial chamber $(\mathrm{cm})$ of initial nests of Atta sexdens rubropilosa.

\begin{tabular}{lllll}
\hline & & \multicolumn{3}{c}{ Chamber } \\
\cline { 3 - 5 } Experimental series & Tunnel & Length & Height & Width \\
\hline Single digging & $12.0 \pm 2.02$ & $3.93 \pm 0.71$ & $2.11 \pm 0.38$ & $2.78 \pm 0.38$ \\
Double digging I & $10.82 \pm 2.48$ & $3.35 \pm 0.70$ & $2.09 \pm 0.40$ & $2.78 \pm 0.73$ \\
Double digging II & $8.50 \pm 2.35$ & $3.73 \pm 0.98$ & $1.98 \pm 0.26$ & $2.83 \pm 0.68$ \\
Triple digging I & $10.47 \pm 2.52$ & $3.22 \pm 0.82$ & $1.95 \pm 0.32$ & $2.66 \pm 0.56$ \\
Triple digging II & $8.43 \pm 1.99$ & $2.95 \pm 0.54$ & $1.83 \pm 0.34$ & $2.23 \pm 0.44$ \\
Triple digging III & $7.72 \pm 2.27$ & $3.87 \pm 0.57$ & $1.99 \pm 0.30$ & $2.64 \pm 0.51$ \\
\hline
\end{tabular}


Our results show that carbohydrate content of the queens of Atta sexdens rubropilosa were affected by the increased digging effort, in other words, by the successive excavations experimentally induced. Additionally, Camargo et al. (2013) found that a single worker (body weight $9.65 \pm 1.50$ $\mathrm{mg}$ ) dug on average $0.85 \pm 0.27 \mathrm{~g}$ of soil in 24 hours and consumed approximately $0.58 \pm 0.23 \mathrm{~J}$, a significant energy cost by the workers. Thus, there is a digging cost directly detected by the consumption of total carbohydrates. The queens dug $35.66 \mathrm{~g}$ in the single digging, and when subjected to triple excavation, dug about $87.90 \mathrm{~g}$.

Furthermore, it is known that the oviposition rate is not affected by the digging effort (Camargo et al., 2011), but it does accentuate mortality of these queens. The authors state that there is no clear justification for the queen's mortality based on the depletion of body reserves. There may be two consequences of the successive effort. First, excessive cuticle abrasion due to the increasing digging, with associated water losses as described for harvesting ants (Johnson, 2000; Johnson \& Gibbs, 2004) and second, the accumulation of oxidative damage associated with the intense initial digging activity, as known for flying insects (Magwere et al, 2006; Sohal \& Buchan, 1981).

Based on our results it can be concluded that the amount of carbohydrates is the main energetic resource used for the nuptial flight for males and gynes, and digging nest for queens of leaf-cutting ants, when they dug two or three times.

\section{References}

Amante, E. (1972). Preliminary observations on the swarming behavior of the leaf-cutting ants Atta capiguara (Hymenoptera: Formicidae). Journal of Georgia Entomological Society, 7: 82-83.

Autuori, M. (1942). Contribuição para o conhecimento da saúva (Atta spp - Hymenoptera - Formicidae). Arquivos do Instituto Biológico, 13: 137-50.

Bollazzi, M., Kronenbitter, J., Roces, F. (2008). Soil temperature, digging behaviour, and the adaptive value of nest depth in South America species of Acromyrmex leafcutting ants. Oecologia, 158: 165-175. doi: 10.1007/s00442008-1113-z.

Camargo, R.S. \& Forti, L.C. (2013) A. Queen lipid content and nest growth in the leaf cutting ant (Atta sexdens rubropilosa) (Hymenoptera: Formicidae). Journal of Natural History, 47: 65-73. doi: 10.1080/00222933.2012.738836.

Camargo, R.S. \& Forti L.C. (2013) B. Esforço de escavação e teor de lipídios em rainhas da formiga cortadeira Atta sexdens rubropilosa. Ciência Rural, 43: 1371-1374.

Camargo, R.S.; Fonseca, J.A.; Lopes, J.F.S.; Forti L.C. (2013). Influência do ambiente no desenvolvimento de colônias iniciais de formigas cortadeiras (Atta sexdens rubropilosa). Ciência Rural, 43: 1375-1380.
Camargo, R.S., Forti, L.C., Fujihara, R.T. \& Roces, F. (2011). Digging effort in leaf-cutting ant queens (Atta sexdens rubropilosa) and its effects on survival and colony growth during the claustral phase. Insectes Sociaux, 58: 17-22. doi 10. 1007/s00040-010-0110-5.

Chapman, R.F. (1998). The insects: structure and function. Cambridge: Cambridge University Press. 770 p.

Cook, S.C., Eubanks, M.D., Gold, R.E. \& Behmer, S.T. (2010). Colony-level macronutrient regulation in ants: mechanisms, hoarding and associated costs. Animal Behaviour, 79: 429-437. doi: 10.1016/j.anbehav. 2009.11.022.

Cherrett, J.M. (1968). A flight record for queens of Atta cephalotes L. (Hym., Formicidae). Entomologist Monthly Magazine, 104: 255-256.

Cunha, W.H.A. (1968). Observações acêrca do comportamento da iça Atta sexdens rubropilosa Forel, 1908 (Hymenoptera: Formicidae) na fundação do formigueiro. Ciência e Cultura, 20: 233-234. doi: 10.1590/S0103-84782013000800005.

Della Lucia, T.M.C., Vilela, E.F., Moreira, D.D.O., Bento, J.M.S. \& Dos Anjos, N. (1990). Egg-laying in Atta sexdens rubropilosa, under laboratory conditions. In: Vander Meer R.K. \& Jaffe, K. (Eds.) Applied Myrmecology - A World Perspective. p.173-179.

Della Lucia, T.M.C., Moreira, D.D.O., Oliveira, M.A. \& Araújo, M.S. (1995). Perda de peso de rainhas de Atta durante a fundação e o estabelecimento das colônias. Revista Brasileira de Biologia, 55: 533-536.

Dubois, M., Gilles, K.A., Hamilton, J.K., Rebers, P.A., Smith, F. (1956). Colorimetric method for determination of sugars and related substances. Analytical Chemistry, 26: 350-356.

Eidmann, H. (1935). Zur Kenntnis der Blattschneiderameise Atta sexdens L., insbesondere ihrer Ökologie. Zeitschrift fur Angewandte Entomologie, 22: 185-436.

Fröhle, K. \& Roces, F. (2012). The determination of nest depth in founding queens of leaf-cutting ants (Atta vollenweideri): idiothetic and temporal control. Journal of Experimental Biology, 215: 1642-1650. doi: 10.1242/jeb.066217.

Fujihara, R.T., Camargo, R.S. \& Forti, L.C. (2012). Lipids and energy contends in the bodies of queens of Atta sexdens rubropilosa Forel (Hymenoptera: Formicidae): pre and post nuptial flight. Revista Brasileira de Entomologia, 56: 73-75. doi: 10.1590/S0085-56262012005000015.

Hölldobler, B.\&Wilson,E.O.(1990). The Ants. Cambridge:Harvard University Press, $732 \mathrm{p}$.

Johnson, R.A. (2000). Water loss in desert ants: caste variation and the effect of cuticle abrasion. Physiological Entomology, 25: 48-53. doi: 10.1046/j.1365-3032.2000.00170.x

Johnson, R.A. \& Gibbs, A.G. (2004). Effect of mating stage on water balance, cuticular hydrocarbons and metabolism in the 
desert harvester ant, Pogonomyrmex barbatus. Journal of Insect Physiology, 50: 943-953. doi: 10.1016/j.jinsphys.2004.07.006

Jutsum, A.R. \& Quinlan, R.J. (1978). Flight and substrate utilisation in laboratory-reared males of Atta sexdens. Journal of Insect Physiology, 24: 821-825. doi: 10.1016/00221910(78)90102-6.

Magwere, T., Pamplona, R., Miwa, S., Martinez-Diaz, P., Portero-Otin, M., Brand, M.D. \& Partridge, L. (2006). Flight activity, mortality rates, and lipoxidative damage in Drosophila. Journal of Gerontology: Biological Science, 61A: 136-145.

Passera, L., Keller, L., Grimal, A., Chaitems, D., Cherix, D., Fletcher, W., Rosengren, R., Vargo, E.L. (1989). Carbohydrates as energy source during the flight of sexuals of the ant Formica lugubris (Hymenoptera: Formicidae). Entomologia Generalis, 15: 25-32. doi: 10.1127/entom.gen/15/1990/25.

Passera, L. \& Keller, L. (1990). Loss of mating flight and shift in the pattern of carbohydrate storage in sexuals of ants (Hymenoptera; Formicidae). Journal of Comparative Physiology, 160: 207-211. doi: 10.1007/BF00300955.

Peakin, G.J. (1972). Aspects of productivity in Tetramorium caespitum L. Ekologia Polska, 20: 55-63.
Ribeiro, F.J.L. (1972). Um estudo sobre o comportamento da fêmea durante a fundação da colônia em Atta sexdens rubropilosa Forel, 1908 (Hymenoptera: Formicidae). Tese Doutoramento, Universidade São Paulo, Psicologia.

Seal, J.N. (2009). Scaling of body weight and fat content in fungus gardening ant queens: does this explain why leafcutting ants found claustrally? Insectes Sociaux, 56: 135-141. doi: $10.1007 / \mathrm{s} 00040-009-0002-8$.

Silva, A., Bacci, M., Siqueira, C.G., Bueno, O.C., Pagnocca, F.C., Hebling, M.J.A. (2003). Survival of Atta sexdens workers on different food sources. Journal of Insect Physiology, 49: 307-313. doi: 10.1016/S0022-1910(03)00004-0.

Sohal, R.S. \& Buchan, P.B. (1981). Relationship between physical activity and life span in the adult housefly, Musca domestica. Experimental Gerontology, 16: 157-162. doi: 10.1016/0531-5565(81)90040-1.

Staab, M. \& Kleineidam, C.J. (2014). Initiation of swarming behavior and synchronization of mating flights in the leaf-cutting ants Atta vollenweideri Forel, 1893 (Hymenoptera: Formicidae). Myrmecological News, 19: 93-102. Retrieved from: http:// www.myrmecologicalnews.org/cms/images/pdf/volume19/mn 19_93-102_non-printable.pdf. 